doi.org/ 10.51891/rease.v7iro.2665

\title{
ANÁLISE SOBRE RISCO POLÍTICO E AS ABORDAGENS COMPARATIVAS DE BAIXO PARA CIMA, DE NÍVEL MÉDIO
}

\author{
POLITICAL RISK ANALYSIS AND DOWN-UP, MEDIUM-LEVEL COMPARATIVE \\ APPROACHES
}

\author{
Luiz Antônio Santos ${ }^{1}$ \\ Vania Carla Barbosa Santos²
}

RESUMO: Esta é uma análise crítica, que tem como foco o modelo de risco político fundamentado em abordagens comparativas do tipo de baixo para cima (bottom-up), de nível médio (mid-level), e análise comparativa cruzada (cross-country). O objetivo principal da análise é avaliar as possíveis deficiências destes modelos analíticos. São objetivos específicos: oferecer estratégias para mitigação de riscos; avaliar o método, seus pressupostos básicos e sua aplicabilidade; propor aprimoramentos para o método de gerenciamento de risco. Este trabalho apresenta uma breve revisão dos conceitos associados aos métodos de análise e gerenciamento de risco baseado em abordagem comparativa do tipo de baixo para cima, de nível médio e análise cruzada. Busca-se definir a abordagem, evidenciar suas fragilidades e propor alternativas. Trazendo informações importantes para o setor político bem como administrativo na administração pública.

Palavras chaves: Risco político. Nível baixo. Nível médio. Comparativa Cruzada.

ABSTRACT: This is a critical analysis, which focuses on the political risk model based on bottom-up, mid-level, and cross-country comparative approaches. The main objective of the analysis is to assess the possible shortcomings of these analytical models. The specific objectives are: to offer risk mitigation strategies; evaluate the method, its basic assumptions and its applicability; propose improvements to the risk management method. This paper presents a brief review of the concepts associated with risk analysis and management methods based on a comparative approach of the bottom-up, mid-level and cross-analysis. It seeks to define the approach, highlight its weaknesses and propose

\footnotetext{
${ }^{I}$ Mestre em Direito pelo Instituto Brasileiro de Desenvolvimento e Pesquisa (IDP). Doutorando pelo ITEInstituto Toledo de Ensino. Advogado Criminalista. Graduado em Direito pela Faculdade Mario Schenberg,Graduado em Filosofia pela Unisul. Pós-graduado em Direito Penal e Processo Penal pela Faculdade Leonardo da Vince. Pós-graduado em Medicina Legal/Ciências Forenses, Pós-graduado em Direito Médico, Pós-graduado em Ciências Criminais pela PUC. É especialista no Tribunal do Júri e na Vara da Infância e Juventude. E-mail: contato@luizantonio.adv.brhttp://orcid.org/oooo-ooo2-3171-5522 ${ }^{2}$ Mestranda em psicologia pela Universidade de São Paulo (USP), é graduada em Psicologia, especializada em Psicologia Clínica Hospitalar (Hospital das Clínicas da Faculdade de Medicina da Universidade de São Paulo, HC - FMUSP, Brasil. Atualmente é psicóloga clínica no consultório particular, com experiencia na área da Psicologia, e Psicanálise. E-mail: vania.carla@uol.com.br.
} 
alternatives. Bringing important information to the political sector as well as administrative in public administration.

Keywords: Political risk. Low level. Mid-level. Cross-Comparative.

\section{INTRODUÇÃO}

Esta é uma análise crítica, que tem como foco o modelo de risco político fundamentado em abordagens comparativas do tipo de baixo para cima (bottom-up), de nível médio (mid-level), e análise comparativa cruzada (cross-country). O objetivo principal da análise é avaliar as possíveis deficiências destes modelos analíticos. São objetivos específicos:

- Oferecer estratégias para mitigação de riscos;

- Avaliar o método, seus pressupostos básicos e sua aplicabilidade;

- Propor aprimoramentos para o método de gerenciamento de risco.

A gerência de riscos incluiu na esfera pública um componente de esforço para o aprimoramento da administração, pois é muito importante este instrumento que alcança os melhores resultados pelas organizações. Também tem o potencial de aperfeiçoar a qualidade das entregas à sociedade, tornando-se relevante torna-se que a sua aplicação observe a dificuldade ou complexidade advinda da produção das políticas públicas.

Observa-se que a literatura de implementação tem o condão de mostrar as variáveis dinâmicas e não neutras na atuação do Estado, que associa as incertezas que podem trazer riscos à obtenção da finalidade pública. Então, sob os aspectos metodológicos, esta pesquisa traz na teoria a estrutura que permitiram o desenvolvimento de dois modelos que possa identificar os riscos - que justamente são: I) o modelo de risco político fundamentado em abordagens comparativas do tipo de baixo para cima (bottom-up), de nível médio (midlevel),e 2) análise comparativa cruzada (cross-country).

Por isso é importante e necessário entender como funciona o modelo de risco político fundamentado nas abordagens com as comparações do tipo de baixo para cima que em inglês significa (bottom-up), de nível médio que também em inglês significa (mid-level), e análise comparativa cruzada no inglês é o (cross-country). 


\section{Delimitação da Pesquisa}

Este trabalho apresenta uma breve revisão dos conceitos associados aos métodos de análise e gerenciamento de risco baseado em abordagem comparativa do tipo de baixo para cima, de nível médio e análise cruzada. Busca-se definir a abordagem, evidenciar suas fragilidades e propor alternativas. Trazendo informações importantes para o setor político bem como administrativo na administração pública.

\section{O que é o Risco Político?}

O Risco também pode ser definido, conforme a Controladoria Geral da União CGU, como a possibilidade de ocorrência de um evento, cujos impactos impeçam a obtenção de resultados. Os riscos tradicionalmente considerados possuíam uma natureza, até certo ponto, previsível. Podiam ser limitados em poucas categorias, como de integridade, operacional, financeiros e legais, conforme a CGU. (CUNHA FILHO, 2020, p. 2).

Desta forma, pode-se entender como Risco político quando os investimentos sofrem mudanças ou instabilidades políticas em determinado país, assim é chamado de risco político, pois há vários fatores determinantes como a mudança de presidente de determinado país, ou mesmo mudança da composição dos órgãos legislativos, bem como quando acontece um golpe de Estado por exemplo, ou até um impeachment de um governante, como foi o caso do que ocorreu no Brasil com a presidente Dilma, entre outras e outras coisas mais.

Esta redução na categorização dos riscos permite análises comparativas entre fenômenos tão complexos como as grandes sociedades pós-modernas. As análises do tipo Bottom-Up (de baixo para cima), propõem que as ameaças sejam avaliadas em uma escala hierárquica, de maneira que na base os especialistas analisam os requisitos técnicos para gestão de riscos e, a cada nova camada analítica, os fatores envolvidos são considerados de forma mais genérica, até a tomada final de decisões, no topo da cadeia de controle de riscos. (BRAGA, 2018). 
Este tipo de avaliação visa um distanciamento dos tomadores de decisão em relação a eventos específicos, de maneira que se concentrem em grandes fenômenos críticos. Os avaliadores distanciados são os Hedgehog (porcos-espinho, na visão de Arquíloco), tomadores de risco que enxergam apenas uma coisa grande e importante. A abordagem Bottom- $U_{p}$ é frequente na gestão de riscos políticos e coloca em relevo a participação da linha de frente (as raposas) nos processos na tomada de decisão, com autonomia relativa. Entretanto, a sistemática de gestão de riscos assim desenhada envolve fragilidades, como as vantagens de simplicidade analítica, distanciamento crítico e atribuição de legitimidade à gestão de riscos. (BRAGA, 2018; CUNHA FILHO, 2020).

Outra ferramenta amplamente utilizada por grandes agências de Rating e tomadores de decisão é a comparação entre economias nacionais e outras grandes organizações por meio de um fator médio de risco, como o Risco País. Por padrão, a maioria das agências de classificação consideram os USA como risco mínimo (AAA) e, a partir do cálculo da diferença entre os juros pagos para o mercado por outros países, bem como pela consideração de outros fatores de risco político, atribuem notas comparativas às demais sociedades, que podem ser estendidas às suas principais organizações produtivas.

$\mathrm{Na}$ análise comparativa cruzada de riscos (cross-country) são feitas comparações matemáticas, a partir de indicadores sociais. Healy (2003), recorre ao coeficiente de regressão $\beta$ para comparar fatores sociais como mortalidade, pobreza e desigualdade entre Espanha, Portugal etc... A principal dificuldade deste viés analítico é que correlação não é causalidade.

As comparações de quantidade, emprestam legitimidade matemática à análise, mas não explicam a causa dos fenômenos sociais. Tanto as análises comparativas cruzadas quanto as do tipo mid-level, focadas em técnicas matriciais de análise, pecam pelo mesmo motivo, as abstrações quantitativas afastam o analista das características contextuais do fenômeno descrito.

Um exemplo prático é a utilização, amplamente aceita, do Produto Interno Bruto (PIB) como indicador de riqueza do país. Ora, a soma das riquezas de um país não mostra 
por quantas pessoas ela é dividida, e diz pouco sobre questões importantes, como qualidade de vida, analfabetismo, pobreza etc... Quando se considera a balança de serviços na problemática, o PIB, ele se torna um indicador ainda menos eficaz, uma vez que as riquezas internacionais manipuladas em um país como royalties, ou direitos autorais, é contabilizada no PIB nacional e consumida em outra região.

\section{Impactos dos Riscos Políticos}

De acordo com o (Insight Geopolítica) o risco político altera títulos de dividas, afeta ações e as commodities, tudo depende das variáveis para entender o tamanho do impacto. Podem ocorrer várias consequências drásticas e uma delas pode ser a troca de ministros de Estado, porque geram incertezas na parte dos mercados.

Segue abaixo uma tabela para explicar com mais clareza sobre estes impactos e apresentaras possíveis consequências- diretas, indiretas nos mercados e na política:

\begin{tabular}{|c|c|c|}
\hline & Ações Governamentais & Ações não-governamentais \\
\hline Impacto direto & $\begin{array}{l}\text { - Acarreta a desvalorizar de moeda- do Controle } \\
\text { monetário } \\
\text { - Ocorre o Calote na dívida } \\
\text { - Mudanças de regulação } \\
\text { - Podem confiscar os ativos de bancos }\end{array}$ & $\begin{array}{l}\text { - Boicotes- Greves } \\
\text { - Terrorismo } \\
\text { - Guerra civil }\end{array}$ \\
\hline $\begin{array}{l}\text { Impacto indireto que } \\
\text { acarretam incertezas nos } \\
\text { mercados }\end{array}$ & \begin{tabular}{|l} 
- Declarações de guerra- Mudanças na \\
composição do governo \\
- Declarações públicas \\
- Podem ocorrer Eleições
\end{tabular} & \\
\hline
\end{tabular}

Quadro or Fonte( http://www.insightgeopolitico.com/risco-politico/,p.or)

De acordo com o Professor Dr. Brasiliano da revista brasiliano, pode ocorrer o impacto positivo e ou negativo vejam:

Risco implica na criticidade, probabilidade versus impacto, que pode ser positiva ou negativa. A criticidade positiva é o ganho, a vantagem que a empresa ou governo terá em determinado projeto em sua execução. Embora tenha havido riscos, estes quando mensurados direcionaram para uma vantagem financeira, competitiva e ou operacional. Já a criticidade negativa é perda, falha, na execução de um determinado projeto, podendo gerar significativos impactos em sua imagem, em seu fluxo de caixa e respectivo patrimônio. (Brasiliano, 2019, p.or) 
Conforme Wafo (1998, p. oI-I5), existem muitas preocupações relacionadas ao risco político como por exemplo os investimentos externos, assim entende que os investidores estrangeiros observa muito se determinado país tem uma economia estável, bem como ficam de olho se naquele país que querem investir não tem conflitos políticos, ausência de regulamentação, ausência de inflação alta, se o governo acolhe e trata justamente o estrangeiro, se o governo não pratica políticas arbitrárias, capacidade de vender ou liquidar o que é investido e depois para retirada do fundo do país.

\section{Importância do risco político}

Para Kobrin (1979, p. 67-8o) entendia que quando a empresa se expande internacionalmente, pode enfrentar riscos políticos que não foram dentro do seu país de origem, pois justamente por causa da necessidade de fazer ao mesmo tempo operações em diferentes ambientes, esta é uma compreensão prevista na política quando não conseguem atender as demandas de gerenciamentos atuais. Outra coisa não menos importante, são as mudanças repentinas na política em países hospedeiros, com isso, podem também ocorrer com certa frequência estas mudanças abruptas e isso podem provocar surpresas talvez indesejáveis.

Desta forma, as empresas, quando praticam aventuras no estrangeiro podem perceber os aspectos da política como sendo os mais importantes em que vão realizar os seus objetivos.

\section{Variáveis políticas}

O professor Howell (1994, p. 70-91,) mostra a variável considerando a fragmentação do espectro político, e atualmente é considerado como influenciador de partidos políticos dentro de determinado governo que tem o regime democrático. Considerando a varável como um alto risco político quando se leva em consideração o alto número de partidos políticos, e isso influencia as decisões do governo. Desta forma, quanto maior é o número de partidos políticos em determinado Estado Democrático, maior é a dificuldade e isso 
impede ao governo implantar mudanças que favoreça a internacionalização e maior é o risco político.

Ainda Howell demonstra que, de outro lado, o autoritarismo/totalitarismo o modo que este autoritarismo tem interferido deixando instável o empreendimento, e assim, o fator de alto risco político geralmente vai impor certas medidas de restrição, como medidas coercitivas que é capaz de refletir na perspectiva das ações arbitrárias daquele que governa havendo mudanças abruptas nas regras e na implementação das decisões, por causa da manipulação do governo de um país. Ele diz que quanto maior é o governo autoritário maior é o risco político para efetuar a internacionalização, assim, entendese que um governo democrático, ou seja, onde há a democracia, o país apresenta menor possibilidade de risco político.

\section{Dois fenômenos recentes}

Dois fenômenos recentes, inimagináveis a algumas décadas, e atribuídos ao novo tipo de risco político, são a saída do Reino Unido do bloco europeu (Brexit) e a eleição do presidente estadunidense Trump ${ }^{3}$. Trump aconselhou o Reino Unido a não pagar a conta Brexit da separação da União Europeia. Tais eventos foram mobilizados, quase completamente no nível básico da tomada de decisões (bottom), de uma forma complexa, articulada por pequenos grupos de atores e de maneira ainda pouco compreendida. (RICE, ZEGART, 2018, p. 223).

\section{Fragilidades}

Tomando o Brexit e a primeira Eleição de Trump como casos de estudo, observamos que nem uma análise Bottom- $U_{p}$, nem as comparativas de risco médio e cruzada, seriam efetivas na previsibilidade, ou gestão de riscos relativos a tais fenômenos, uma vez que, ao afastar-se do fenômeno eleitoral, para avaliá-lo de cima, como fazem os grandes tomadores de decisão, adota-se uma perspectiva que oculta as pequenas peculiaridades que estiveram presentes nestes dois episódios.

3 Em 2016 a empresa FedEx calculou em 25\% as chances de vitória de Trump e do Brexit. (RICE, ZEGART, 2018, p. 59). No Brasil, evento similar é classificado como "ascensão improvável desse estranho". (TAYLOR, 2020). 
Por exemplo, como se poderia gerir, por meio da decisão de grandes agentes políticos, ou em uma perspectiva distanciada e abstrata, o trânsito de hackers do leste europeu na disseminação de fake news (mensagens difamatórias), ou prever o altíssimo potencial deste recurso comunicativo em um ambiente político polarizado, cujas discussões e decisões foram influenciadas privativamente em redes sociais caoticamente integradas? Tal polarização foi tardiamente percebida e crucial, tanto para a eleição de Trump, quanto para o Brexit, quase como uma máquina eleitoral barata, que estava à venda e prontamente disponível.

Uma análise de risco médio, fundamentada em poucas abstrações econômicas e sociais, da mesma forma, teria pouco, ou nenhuma valia em relação à capacidade de avaliar o risco associado ao potencial de engajamento de eleitores de extrema direita em uma situação tão inusitada, quanto a grande articulação eleitoral observada nas redes sociais, orientada por ódio, difamação e protegida pelo anonimato, uma vez que tais fatores seriam, normalmente, repudiados em um ambiente eleitoral.

Trata-se nestes casos, da estruturação de um novo e inusitado tipo de corrupção da democracia, para o qual não se podia estar preparado, uma vez que os mecanismos básicos de funcionamento da corrupção são pouco conhecidos e altamente adaptáveis, conforme Taylor. (2019, p. 1312).

\section{Soluções propostas}

Uma das soluções possíveis para a gestão de riscos políticos na sociedade da informação, proposta por Rice e Zegart (2018, p. 223), é a mudança de foco, da visão externa para a interna e da análise macro para a micro. A pandemia de Covid-ı́ é a prova final de que o nível de incerteza normal é o máximo (o risco de morte). Por isso, não importa tanto qual é o nível de risco político atual, mas sim o nível ao qual cada organização está preparada para se expor. Os novos horizontes tornaram a resiliência e a capacidade de suporte ao risco mais relevantes para a tomada de decisões do que o conhecimento que dispomos sobre cada ameaça. 
O primeiro passo para uma nova abordagem, em relação à gestão de risco, se inicia pelo autoconhecimento e pelo fortalecimento das defesas internas das organizações, em relação aos impactos negativos que, certamente virão. $O$ segundo fator integra a perspectiva interna (tolerância ao risco) à externa (contingência), ou seja, ao invés de avaliar todos os grandes riscos políticos setoriais, atitude típica de porco-espinho (Hedgehog), basta a atitude de raposa (fox), na qual importa apenas conhecer muito bem, reagir rapidamente e conforme aos pequenos e muitos riscos específicos, aos quais esta organização está exposta. Essas duas perspectivas devem ser integradas de forma incremental, a fim de permitir soluções práticas e sistemáticas para enfrentar as ameaças de forma equilibrada. (TAYLOR, 2020, p. 595-604).

\section{Estratégias de internacionalização}

Conforme foi analisado as possibilidades de expandir e chegar a outros países, aqueles que são empreendedores tem que decidir onde tem os melhores meios de entrada no caso de um mercado estrangeiro. De acordo com o que se entende sobre a literatura de internacionalização. Assim, encontra-se cinco condutas essenciais de expansão no mercado

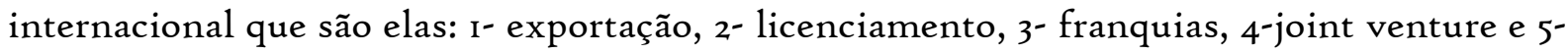
subsidiária própria. Com a consequência de se levar a cabo esta tarefa, devem ser designadas com estratégias de internacionalização, já elas dependem de atitudes e certas atividades do empreendedor bem com da empresa que demanda as tomadas de decisões e de disponibilidade dos recursos que ocorrem nos eventos.

De acordo com Rios (2009, p. I44-156 apud GARRIDO, VIEIRA, SLONGO et al., 2009), é baseado em arranjo institucional o jeito que se da a entrada em um mercado internacional, tornando-se em possibilidades a inserção dos produtos de tecnologia, as habilidades humanas, o gerenciamento e ainda os outros recursos de determinadas empresas que venham a atura nos mercados internacionais.

Desta forma, se utilizam de estratégias que contemplam os objetivos, as metas, os recursos e as politicas que direcionam os negócios internacionais de alguma empresa, por 
determinado período que seja suficiente e que atinjam o crescimento sustentável no mercado externo.

Assim sendo, o autor acima citado apresenta sugestão para que os modos de entrada sejam classificados da seguinte maneira:

I- de exportação (exportação indireta, exportação direta); (2) contratuais (licenciamento, franquia, acordos técnicos, contratos de serviços, contratos de gerenciamento, contratos de produção, entre outros); (3) de entrada de investimentos (investimentos individuais por meio de novos empreendimentos ou aquisições e joint ventures mediante novos empreendimentos ou aquisições).

Com isso, se a empresa seguir as determinações corretas terá grande chance de êxito na prática de seus negócios externos no que tange a empreitada internacional, e terá menos risco de resultados indesejados.

\section{CONSIDERAÇÕES FINAIS}

A análise crítica aqui exposta, ainda que superficial, mostra a necessidade de readequar as técnicas habituais de avaliação e gestão de risco. A abordagem do tipo BottomUp possui a deficiência de ocultar dos grandes tomadores de risco aspectos específicos, complexos e variados, que podem ser determinantes para o curso dos eventos em uma sociedade da informação.

A comparação entre grandes agentes sociais, como países, por meio de cálculo de risco médio, ou análise comparativa cruzada, se mostra ainda mais ineficaz, no contexto contemporâneo, por distanciar os analistas dos dados referentes às contingências de cada organização. Assim, propõe-se uma abordagem alternativa, focada em dois preceitos sistêmicos: é preciso fortalecer a resiliência das organizações, visto que a perspectiva é de risco máximo, de maneira que o domínio da resistência interna se torna mais relevante do que entender as ameaças em si.

Além disto, é necessário conectar, de forma integrada e incremental, a disposição para o risco ao contexto das organizações, aprendendo de forma pormenorizada os pequenos e múltiplos riscos, o que permite reações rápidas, conscientes, organizadas e sistemáticas às mais variadas contingências. 
Também, neste trabalho, investigou-se os riscos políticos, os aspectos dos riscos políticos, bem como os processos de internacionalização em determinada empresa, e ainda trouxe um resumo do que seja as varáveis políticas, e os impactos que o risco pode oferecer que acarretam prejuízos na esfera política, econômica e social de um país.

Foi utilizado a coleta de informações como metodologia, e também reunido conteúdos bibliográficos para definir e entender a política de risco.

Assim, foi observado que a abordagem tipo Bottom-Up possui deficiências e precisa de aperfeiçoamento, que há necessidade de readequar certas técnicas para a gestão de risco. Foi observado também que num país onde se tem um governo ditatorial, que a política sofre e com isso o risco é muito maior, o que gera desconfiança e é capaz de colocar em risco qualquer tipo de investimentos externos no país afetando assim na economia do país além do risco político.

Por fim, em relação ao o risco político, foi observado que este pode sofrer alguns resultados indesejados e o resultado disso é o da instabilidade política e a mudança no governo como por exemplo ter que trocar o presidente de um país inclusive por meio de golpe de Estado, ou até mesmo por meio de impeachment.

\section{REFERÊNCIAS}

BRAGA, M. V. de A. "Risco Bottom Up: Uma reflexão sobre o desafio da implementação da gestão de riscos no setor público brasileiro", Revista da CGU, v. 9, n. I5, I jan. 2018. DOI: I0.36428/revistadacgu.v9i15.103. Disponível em: https://ojs.cgu.gov.br/index.php/Revista_da_CGU/article/view/ı03. Acesso em: 5 nov. 2020 .

BRASILIANO, Antonio Celso Ribeiro https://www.brasiliano.com.br/revista-gr-136-I37risco-politico, acesso em 22/o9/2020.

CUNHA FILHO, M. Risk assessment in Brazil's federal government. . Law School IDP, [s.n.]. . Acesso em: 5 nov. 2020. , 2020

HEALY, J. D. "Excess winter mortality in Europe: a cross country analysis identifying key risk factors", Journal of Epidemiology \& Community Health, v. 57, n. Io, p. 784-789, I out. 2003. DOI: 10.1136/jech.57.10.784. 
HOWELL, L. D; CHADDICK, B. Models of Political Risk for Foreign Investment and Trade: An Assessment of Thee Approaches. The Columbia Journal of World Business, v. 29, n. 3, autumni994. Disponível em: <Disponível em:

http://www.sciencedirect.com/science/article/pii/oo22542894900485 >. Acesso em: 20 set. 2020.

»http://www.sciencedirect.com/science/article/pii/oo22542894900485

INSIGHT, Geopolítico: http://www.insightgeopolitico.com/risco-politico/_acessado em 20/09/202I.

KOBRIN, S. J. Political Risk; a Review and Reconsideration. Journal of International Business Studies, v. Io, n. I, p. 67-8o, Spring/Summer 1979. Disponível em: <Disponível em: https://www.jstor.org/stable/154371?seq=I\#page_scan_tab_contents $>$. Acesso em: 20 ago. 2020. »https://www.jstor.org/stable/I5437I?seq=I\#page_scan_tab_contents

RICE, C., ZEGART, A. Political Risk: how businesses and organizations can anticipate global insecurity. I. ed. New York, Twelve, 2018.

RIOS-MORALES, R. et al. Innovative Methods in Assessing Political Risk for Business Internationalization. Research in International Business and Finance, v. 23, n. 2, p. 144-156, 2009. Disponível em:http://www.sciencedirect.com/science/article/pii/So2755319080o0202 >. Acesso em: 4 set. 2020.

TAYLOR, M. M. "Alcançando a Accountability: uma abordagem para o planejamento e implementação de estratégias anticorrupção", Revista da CGU, 2019. Accepted: 2020-04ı7Too:49:o6Z, out. 2020. Disponível em:https://repositorio.cgu.gov.br/handle/I/4435I. Acesso em: 5 nov. 2020.

TAYLOR, M. M. "Coalitions, Corruption, and Crisis: The End of Brazil's Third Republic?", Latin American Research Review, v. 55, n. 3, 2020. DOI: https://doi.org/ro.25222/larr.1264. Acesso em o8 out 2020

WAFO, G. L. K. Political Risk and Foreign Direct Investment. Faculty of Economics and Statistics, University of Konstanz, 1998. Disponível em: <Disponível em: http://kops.unikonstanz.de/handle/123456789/12070 >. Acesso em: 28 set. 2020.

»http://kops.uni-konstanz.de/handle/123456789/12070 